\title{
PERANCANGAN PROTOTYPE SISTEM PERINGATAN INDIKASI KEBAKARAN DI DAPUR RUMAH TANGGA BERBASIS ARDUINO UNO
}

\author{
Petrus Sokibi ${ }^{1}$, Riza Abdi Nugraha ${ }^{2}$ \\ Universitas Catur Insan Cendekia Cirebon \\ J1.Kesambi 202, Kota Cirebon, Jawa Barat.Tlp : (0231)220250. \\ e-mail : petrus.sokibi@cic.ac.id ${ }^{1}$, skyliner3663@gmail.com²
}

\begin{abstract}
ABSTRAK
Menggunakan sistem untuk mendeteksi kebakaran adalah suatu pilihan yang berguna untuk memberikan keamanan ketika terjadi bencana kebakaran. Kemajuan teknologi di bidang elektronika berkembang sangat pesat dalam pembuatan alat-alat yang canggih, yaitu alat yang dapat memberikan banyak manfaat dan mempermudah pekerjaan manusia. Munculnya masalah seperti ketika terjadi kebocoran gas LPG yang dapat menjadi pemicu kebakaran, atau ketika munculnya kobaran api yang bisa menyebabkan kebakaran yang lebih besar. Dalam penulisan ini dijelaskan perancangan sistem peringatan indikasi kebakaran di dapur rumah tangga berbasis Arduino Uno yang berfungsi sebagai pemberi peringatan ketika terdeteksi kebocoran gas LPG atau kobaran api. Berdasarkan permasalahan tersebut kemudian muncul gagasan untuk membuat sistem yang dapat memberikan alarm pemberitahuan. Sistem ini terdiri dari Arduino Uno sebagai pengendali utama dari sistem, Sensor Gas MQ2 sebagai pendeteksi kebocoran gas LPG, Sensor Api sebagai pendeteksi nyala api, Buzzer untuk mengeluarkan bunyi peringatan ketika terdeteksi kebocoran LPG atau kobaran api, dan Modul SIM800L yang berguna untuk mengirimkan pemberitahuan melalui SMS ke nomor yang didaftarkan sebelumnya. Untuk pemrograman Arduino menggunakan aplikasi Arduino IDE. Sistem ini nantinya ketika sensor gas atau sensor api mendeteksi kebocoran gas LPG atau kobaran api, data dari sensor tersebut diproses oleh Arduino Uno, kemudian Arduino Uno menyalakan Buzzer dan mengirimkan pemberitahuan melalui SMS ke nomor penerima yang dituju. Hasil dari penelitian ini adalah sistem peringatan indikasi kebakaran di dapur rumah tangga berbasi Arduino Uno.
\end{abstract}

Kata kunci : Arduino, Sensor Gas, Sensor Api, Buzzer, Modul SIM800L.

\section{ABSTRACT}

Using a system to detect fire is a useful option to provide security when a fire occurs. Technological advancements in the field of electronics are growing very rapidly in the manufacture of sophisticated tools, namely tools that can provide many benefits and facilitate human work. The emergence of problems such as when there is a LPG gas leak that can trigger a fire, or when a fire emerges that can cause a greater fire. In this paper explained the design of a fire indication warning system in the Arduino Uno-based household kitchen that serves as a warning when LPG gas leaks or flames are detected.Based on these problems then the idea arises to create a system that can provide notification alarms. This system consists of Arduino Uno as the main controller of the system, the MQ2 Gas Sensor as a LPG gas leak detector, a Fire Sensor as a flame detector, a Buzzer to issue a warning sound when LPG or flames are detected, and a SIM800L Module which is useful for sending notifications through SMS to the number previously registered. For Arduino programming use the Arduino IDE application. This system later when the gas sensor or fire sensor detects LPG gas leaks or flames, the data from the sensor is processed by Arduino Uno, then Arduino Uno turns on Buzzer and sends an SMS notification to the intended recipient number. The results of this study are a fire indication warning system in the Arduino Uno-based household kitchen.

Keywords : Arduino, Gas Sensor, Flame Sensor, Buzzer, SIM800L Module. 


\section{PENDAHULUAN \\ 1.1 Latar Belakang}

Kemajuan teknologi di bidang elektronika sekarang ini berkembang sangat pesat dan berpengaruh dalam pembuatan alat-alat yang canggih, yaitu alat yang dapat memberikan banyak manfaat dan memiliki ketelitian tinggi sehingga dapat mempermudah pekerjaan yang dilakukan oleh manusia menjadi lebih praktis dan efisien.

Arduino adalah pengendali mikro single-board yang bersifat open source, dirancang untuk memudahkan penggunaan elektronik dalam berbagai bidang. Arduino juga merupakan platform hardware terbuka yang ditujukan kepada siapa saja yang ingin membuat purwarupa peralatan elektronik interaktif berdasarkan hardware dan software yang fleksibel dan mudah digunakan.

Api adalah sesuatu yang dapat menghasilkan panas, cahaya, dan berbagai hasil reaksi kimia lainnya. Penemuan cara membuat api merupakan salah satu hal yang paling berguna bagi manusia, karena dengan api manusia bisa aman dari hewan buas, memasak makanan, dan mendapat sumber cahaya serta menjaga dirinya agar tetap hangat. Selain sesuatu yang berguna, api juga bisa membuat bencana yang bisa menyebabkan kerugian bagi manusia itu sendiri.

Sudah banyak terjadi kasus kebakaran yang menimpa rumah warga dan menyebabkan kerugian materil. Seperti peristiwa kebakaran yang terjadi di kawasan Jalan KH Azhari Kelurahan 14 Ulu Kecamatan Seberang Ulu II, Palembang, Senin (10/10/2016). Kebakaran ini menyebabkan empat rumah hangus terbakar dan dua rumah yang terbakar sebagian. Peristiwa ini diduga disebabkan oleh kebocoran gas LPG karena sempat terdengar suara ledakan yang cukup besar sebelum api membesar dan menghanguskan rumah-rumah tersebut (http://www.tribunnews.com).

Kejadian lainnya terjadi di Kecamatan Grati, Pasuruan, Jawa Timur, Asmawati ditemukan tewas setelah tertimpa atap rumahnya yang terbakar. Saat kebakaran berlangsung, Asmawati tengah tertidur sendirian di dalam kamar. Korban baru menyadari rumahnya terbakar saat sejumlah warga berupaya memadamkan api. Namun nyawanya tidak sempat tertolong karena api cepat membesar (http://www.liputan6.com).

Penulis ingin membuat solusi dengan membuat sistem yang dapat memberikan peringatan ketika adanya indikasi sebuah kebakaran. Atau mendeteksi kebocoran gas LPG yang berguna sebagai tindakan pencegahan terhadap kebakaran. Penulis menggunakan Arduino Uno karena mudah dipahami dan dipelajari oleh orang awam, juga bisa dikreasikan dengan berbagai sensor sesuai dengan apa yang ingin dibuat. Sistem ini dapat memberikan peringatan secara otomatis tanpa harus menekan tombol agar alarm berbunyi, dan juga dapat mengirimkan pemberitahuan melalui SMS ke nomor telepon yang didaftarkan sebelumnya. Terkait dengan penelitian sebelumnya yang dilakukan oleh Sanjaya (2016), yang berjudul "Perancangan Sistem Pendeteksi Kebakaran Menggunakan Arduino Mega ADK dan Sensor Berbasis SMS Gateway" pada penelitian tersebut hanya menggunakan sensor api sebagai pendeteksi kebakaran. Maka penulis ingin menambahkan sensor gas sebagai tambahan untuk mendeteksi adanya kebocoran gas LPG yang dapat memicu terjadinya kebakaran. Berdasarkan latar belakang diatas penulis merancang suatu sistem yang dituangkan dalam skripsi ini dengan judul "Perancangan Prototype Sistem Peringatan Indikasi Kebakaran di Dapur Rumah Tangga Berbasis Arduino Uno".

\subsection{Identifikasi Masalah}

Berdasarkan uraian latar belakang diatas, penulis membuat identifikasi masalah sebagai berikut :

1. Kebocoran gas LPG dapat menjadi pemicu terjadinya kebakaran.

2. Kobaran api dapat menjadi penyebab kebakaran yang lebih besar.

3. Bagaimana membuat sistem yang dapat memberikan peringatan ketika adanya indikasi kebakaran?

\subsection{Batasan Masalah}

Adapun batasan masalah yang penulis lakukan adalah sebagai berikut :

1. Menggunakan Arduino Uno sebagai pengendali utama komponen elektronika yang akan digunakan.

2. Membuat perancangan sistem peringatan indikasi kebakaran menggunakan Arduino Uno, sensor pendeteksi gas, sensor pendeteksi api, buzzer, dan modul GSM SIM 800L. 
3. Sistem peringatan ini diletakkan di dapur rumah tangga.

4. Tidak difungsikan sebagai smoke detector.

5. Sensor gas diletakkan di dekat tabung LPG

6. Sensor api diletakkan di dekat kompor

7. Perancangan sistem ini berupa prototype

\subsection{Tujuan}

Adapun tujuan dari skripsi yang dilakukan antara lain :

1. Dapat mendeteksi dan memberikan peringatan jika terjadi kebocoran gas LPG.

2. Dapat memberikan peringatan ketika terdeteksi kobaran api.

3. Meminimalisir jatuhnya korban karena dapat memberikan peringatan indikasi kebakaran.

\section{KAJIAN PUSTAKA}

\subsection{Mikrokontroler}

Mikrokontroler merupakan chip mikrokomputer yang secara fisik berupa sebuah IC (Integrated Circuit). Mikrokontroler biasanya digunakan dalam sistem yang kecil, murah dan tidak membutuhkan perhitungan yang sangat kompleks seperti dalam aplikasi di PC. Mikrokontroler banyak ditemukan dalam peralatan seperti microwave, oven, keyboard, CD player, VCR, remote control, robot dan lainlain. Mikrokontroler berisikan bagian-bagian utama yaitu CPU (Central Processing Unit), RAM (Random-Access Memory), ROM (Read-Only Memory) dan port I/O (Input/Output). Selain bagianbagian utama tersebut, terdapat beberapa perangkat keras yang dapat digunakan untuk banyak keperluan seperti melakukan pencacahan, melakukan komunikasi serial, melakukan interupsi dan lain-lain. Mikrokontroler tertentu bahkan menyertakan ADC (Analog-To-Digital Converter), USB controller, CAN (Controller Area Network) dan lain-lain.

\subsection{Arduino}

Menurut Djuandi (2011) untuk memahami Arduino, terlebih dahulu harus memahami apa yang dimaksud dengan physical computing. Physical computing adalah membuat sebuah sistem atau perangkat fisik dengan menggunakan software dan hardware yang sifatnya interaktif yaitu dapat menerima rangsangan dari lingkungan dan merespon balik. Physical computing adalah sebuah konsep untuk memahami hubungan antara lingkungan yang sifat alaminya adalah analog dengan dunia digital. Pada prakteknya konsep ini diaplikasikan dalam desain-desain alat atau projek-projek yang menggunakan sensor dan mikrokontroler untuk menerjemahkan input analog ke dalam sistem software untuk mengontrol gerakan alat-alat elektro-mekanik seperti lampu, motor dan sebagainya.

Arduino dikatakan sebagai sebuah platform dari physical computing yang bersifat open source. Arduino tidak hanya sekedar sebuah alat pengembangan, tetapi ia adalah kombinasi dari hardware, bahasa pemrograman dan Integrated Development Environment (IDE) yang canggih. IDE adalah sebuah software yang sangat berperan untuk menulis program, meng-compile menjadi kode biner dan meng-upload ke dalam memory microcontroller. Ada banyak projek dan alat-alat yang dikembangkan dengan menggunakan Arduino, selain itu juga ada banyak modul-modul pendukung (sensor, tampilan, penggerak dan sebagainya) yang dibuat oleh pihak lain untuk bisa disambungkan dengan Arduino. Salah satu yang membuat Arduino banyak digunakan adalah karena sifatnya yang open source, baik untuk hardware maupun software-nya. Diagram rangkaian elektronik Arduino digratiskan kepada semua orang. Pengguna bisa bebas men-download gambarnya, membeli komponen-komponennya, membuat PCB-nya dan merangkainya sendiri tanpa harus membayar kepada para pembuat Arduino. Sama halnya dengan IDE Arduino yang bisa di-download dan di-instal pada komputer secara gratis. 


\subsection{Sensor Gas MQ2}

Sensor Gas MQ2 di gunakan sebagai sensor deteksi Alkohol, H2, LPG, CH4, CO, Asap, dan Propane, Sensor ini cocok di gunakan untuk alat emergensi sebagai deteksi kebocoran gas. Sensor gas ini tersusun oleh senyawa $\mathrm{SnO} 2$, dengan sifat conductivity rendah pada udara yang bersih, atau sifat penghantar yang tidak baik. Sifat conductivity semakin naik jika konsentrasi gas semakin tinggi di sekitar sensor gas. Nilai sensor hanya mencerminkan angka konsentrasi gas yang diperkirakan dalam rentang ketidakakuratan yang diizinkan, ini tidak mewakili konsentrasi gas yang tepat. Deteksi konsentrasi gas tertentu di udara biasanya membutuhkan alat yang lebih tepat dan mahal, yang tidak dapat dilakukan dengan satu sensor gas.

\subsection{Sensor Api}

Sensor api merupakan sensor yang mempunyai fungsi sebagai pendeteksi nyala api yang dimana api tersebut memiliki panjang gelombang antara $760 \mathrm{~nm}-1100 \mathrm{~nm}$. Sensor nyala api ini mempunyai sudut pembacaan 60 derajat, dan beroperasi pada suhu 25-85 derajat Celcius. Untuk jarak pembacaan antara sensor dan objek yang dideteksi tidak boleh terlalu dekat, untuk menghindari kerusakan sensor.

Cara kerja sensor ini yaitu dengan mengidentifikasi atau mendeteksi nyala api dengan menggunakan metode optik. Pada sensor ini menggunakan transduser yang berupa infrared (IR) sebagai sensing sensor. Transduser ini digunakan untuk mendeteksi akan penyerapan cahaya pada panjang gelombang tertentu.

\subsection{Buzzer}

Buzzer merupakan sebuah komponen elektronika yang masuk dalam keluarga transduser, yang dimana dapat mengubah sinyal listrik menjadi getaran suara. Nama lain dari komponen ini disebut dengan beeper. Dalam kehidupan sehari - hari, umumnya digunakan untuk rangkaian alarm pada jam, bel rumah, perangkat peringatan bahaya, dan lain sebagainya. Jenis - jenis yang sering ditemukan dipasaran yaitu tipe piezoelectric. Dikarenakan tipe ini memiliki kelebihan seperti harganya yang relatif murah, mudah diaplikasikan ke dalam rangkaian elektronika.

Pada saat ada tegangan listrik yang mengalir ke rangkaian yang menggunakan piezoelectric, maka akan terjadi pergerakan mekanis pada piezoelectric tersebut. Yang dimana gerakan tersebut mengubah energi listrik menjadi energi suara yang dapat didengar oleh telinga manusia. Piezoelectric menghasilkan frekuensi di range kisaran antara $1-5 \mathrm{kHz}$ hingga $100 \mathrm{kHz}$. Tegangan operasional piezoelectric umumnya yaitu berkisar antara $3 \mathrm{~V}$ hingga $12 \mathrm{~V}$.

\subsection{Modul SIM800L}

Modul SIM800L v2 adalah modul Quad Band GSM/GPRS yang kompatibel dengan Arduino Uno. Untuk versi sebelumya SIM800L tegangan input Vcc nya masih 3.7V - 4.2 V, kalau dapat tegangan langsung 5V bisa menyebabkan kerusakan pada modul SIM800L tersebut, sehingga memerlukan Dc to DC Stepdown untuk menurunkan tegangan dari 5V DC ke 3.7V - 4.2V. Untuk modul SIM800L v2 Vccnya sudah bisa 5V DC sehingga bisa langsung di hubungkan dengan Vcc 5V DC dari arduino, sehingga tidak membutuhkan regulator step down.

\section{ANALISA DAN PERANCANGAN SISTEM}

\subsection{Analisa Sistem}

Dalam pembuatan laporan ini, ada beberapa tahap dalam analisa sistem, yaitu :

1. Analisa Masalah

2. Analisa Kebutuhan Perangkat Keras

3. Analisa Kebutuhan Perangkat Lunak 


\subsection{Perancangan Sistem}

\section{Diagram Blok}

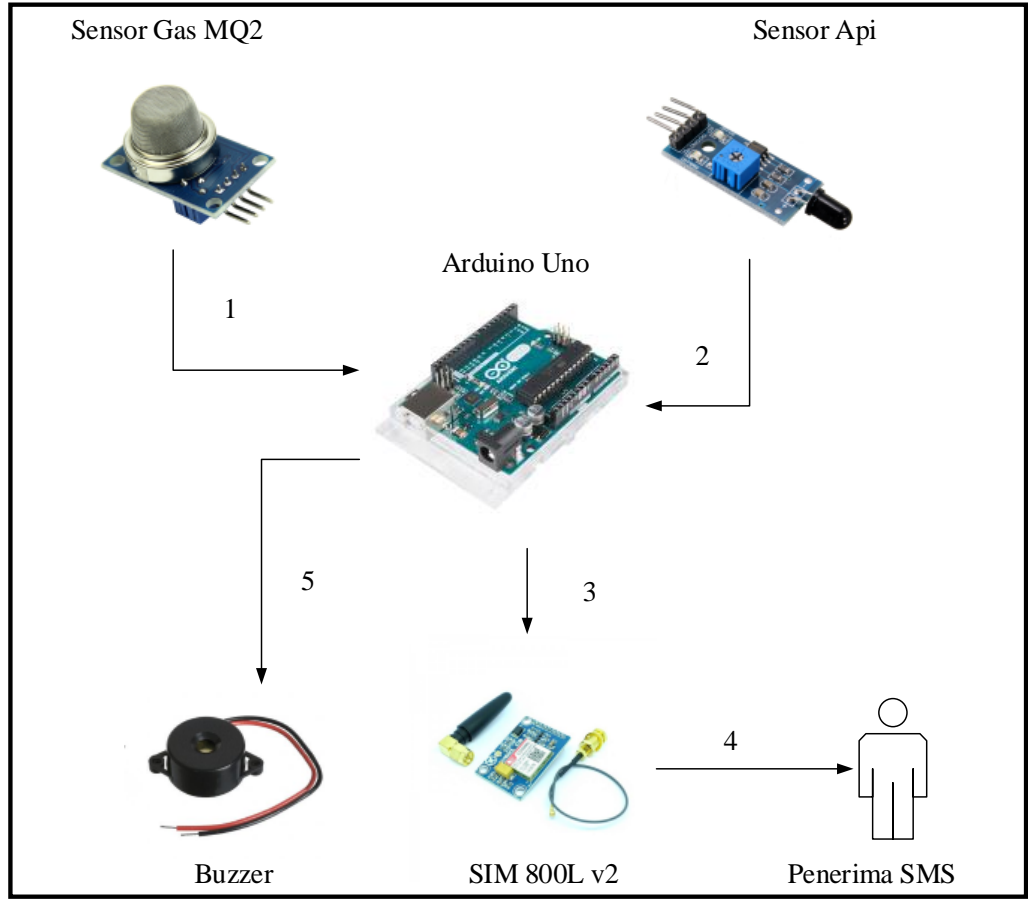

Gambar 1. Diagram Blok

Perancangan sistem peringatan indikasi kebakaran seperti pada Gambar diatas meliputi sensor gas, sensor api, arduino uno, buzzer, dan modul GSM. Dari gambar diatas bisa dijelaskan bahwa ketika sensor gas atau sensor api menerima rangsangan dari lingkungan, kemudian informasi tersebut diolah oleh mikrokontroler yang sebagai pengendali utama kemudian merespon dengan mengirimkan SMS melalui modul GSM dan menyalakan buzzer.

\section{Flowchart Cara Kerja Sistem}

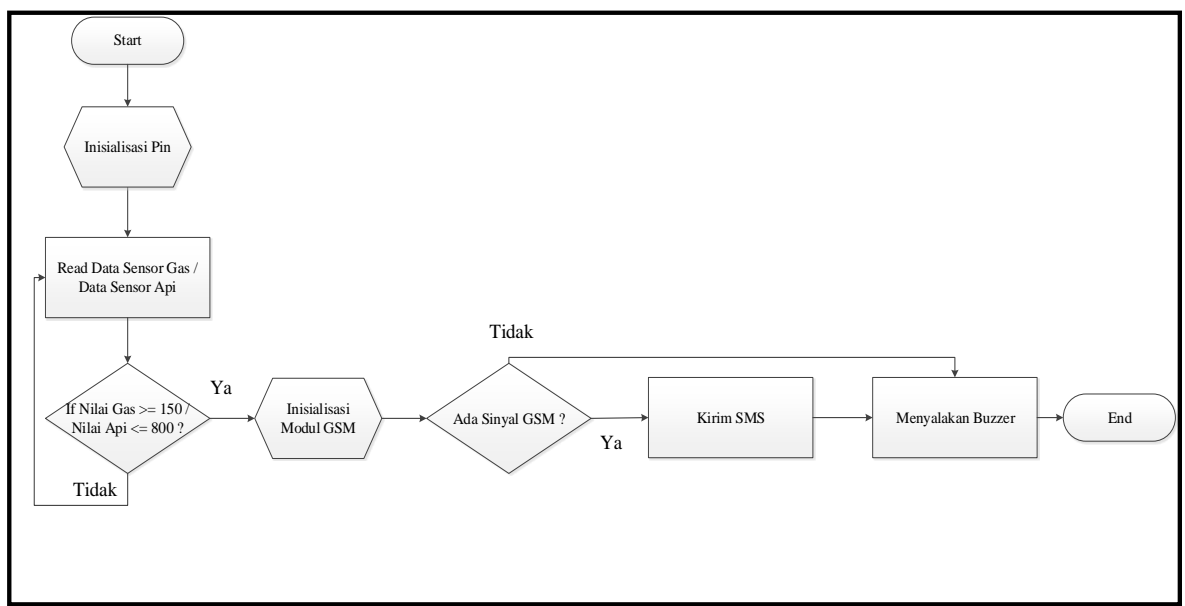

Gambar 2. Flowchart Cara Kerja Sistem

JURNAL DIGIT Vol. 10, No.1 Mei 2020 : 11-22 
Penjelasan flowchart diatas adalah pada awalnya sistem menginisialisasi serial port untuk mengaktifkan sensor gas, sensor api, buzzer dan modul GSM. Lalu ke proses pembacaan sensor gas. Ketika sensor gas mendeteksi adanya gas LPG yang nilainya lebih dari sama dengan 150, maka sensor tersebut memberikan informasi ke Arduino kemudian melakukan perintah untuk mengirimkan SMS pemberitahuan dan menyalakan buzzer. Namun ketika modul GSM tidak mendapatkan sinyal maka hanya bisa melakukan proses menyalakan buzzer. Jika tidak mendeteksi gas maka sistem tidak menyalakan buzzer. Kemudian ke proses pembacaan sensor yang lain yaitu sensor api. Ketika sensor api mendeteksi adanya kobaran api yang nilainya kurang dari sama dengan 800, maka sensor tersebut memberikan informasi ke Arduino kemudian melakukan perintah untuk mengirimkan SMS pemberitahuan dan menyalakan buzzer. Namun ketika modul GSM tidak mendapatkan sinyal maka hanya bisa melakukan proses menyalakan buzzer saja. Jika tidak mendeteksi gas atau api maka sistem tidak menyalakan buzzer dan kembali ke pembacaan sensor.

\section{Perancangan Interkoneksi Breadboard dan Skematik Hardware}

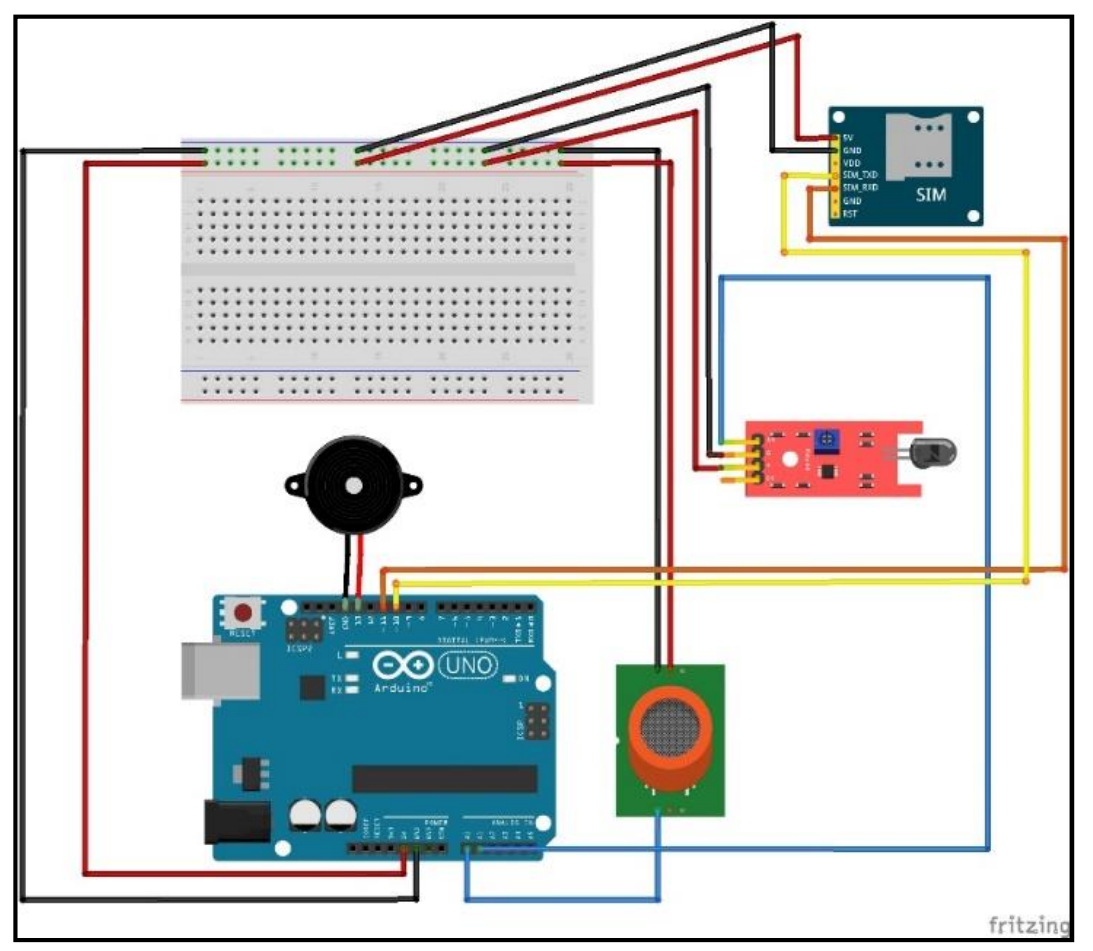

Gambar 3. Rancangan Interkoneksi Breadboard 


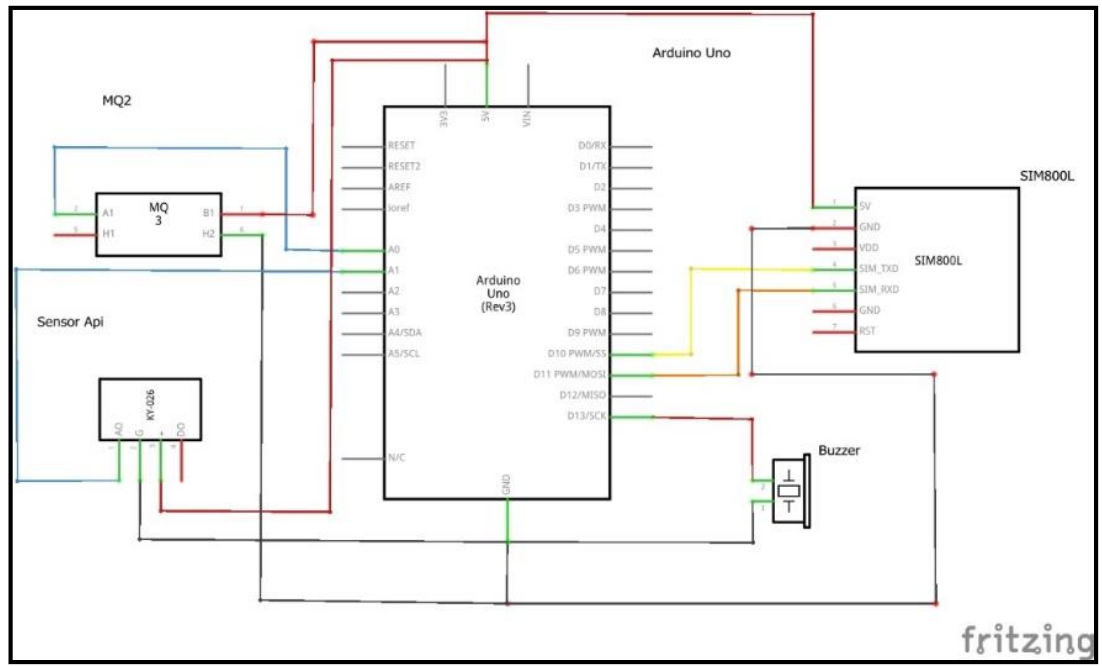

Gambar 4. Rancangan Interkoneksi Skematik

Pada gambar diatas menggambarkan Arduino Uno sebagai pengendali utama yang menghubungkan beberapa modul seperti sensor gas, sensor api, buzzer, dan modul GSM. Sensor gas berfungsi untuk mendeteksi adanya kebocoran gas LPG. Sensor api berguna untuk mendeteksi kobaran api. Buzzer berfungsi untuk memberikan peringatan berupa bunyi. Modul GSM berfungsi untuk mengirimkan pemberitahuan melalui SMS jika terdeteksi kebocoran LPG atau kobaran api.

Berikut penjelasan interkoneksi hardware dalam cara kerja komunikasi antar perangkat sistem peringatan indikasi kebakaran :

1. Pin A0 pada arduino dihubungkan ke pin AO yang ada pada sensor gas. Pin ini berfungsi mengirim data analog ke Arduino. Pin Vcc pada sensor gas dihubungkan ke pin 5V pada arduino. Pin GND pada sensor gas dihubungkan ke pin GND pada arduino

2. Pin A1 pada arduino terhubung ke pin AO pada sensor api. Pin ini berfungsi mengirim data analog ke arduino. Pin GND pada sensor api dihubungkan ke pin GND arduino. Dan pin 5V arduino dihubungkan ke pin Vcc pada sensor api.

3. Pin 13 pada arduino dihubungkan ke pin "+" pada buzzer. Pin ini akan mengirim sinyal high untuk membunyikan buzzer. Dan sinyal low untuk tidak membunyikan buzzer. Pin GND arduino dihubungkan ke pin ground buzzer.

4. Pin 10 pada arduino dihubungkan ke pin SIM_TXD pada modul GSM. Pin 11 pada arduino juga dihubungkan ke pin SIM_RXD pada modul GSM. Pin tersebut berfungsi sebagai jalur komunikasi serial. Pin 5V pada modul GSM dihubungkan ke pin 5V pada arduino. Pin GND dibawah pin 5V pada modul GSM dihubungkan ke pin GND arduino.

\section{IMPLEMENTASI}

\subsubsection{Implementasi Arduino Uno dan Modul yang Digunakan}

Komunikasi Arduino dengan modul sensor lainnya umumnya menggunakan pin digital dan analog, yaitu penggunaan dari modul sensor gas dan modul sensor api yang akan menggunakan pin analog. Sedangkan untuk modul GSM SIM800L akan menggunakan pin digital.

\section{Komunikasi Arduino Uno dan Sensor Gas}

Komunikasi Arduino dan sensor gas digunakan untuk mendeteksi adanya gas di sekitar sensor. Ketika mendeteksi adanya gas, maka sensor gas akan terasa hangat. Sensor gas ini digunakan untuk mendeteksi gas LPG. Penulis menggunakan data analog agar dapat mengukur gas LPG yang terdeteksi. 


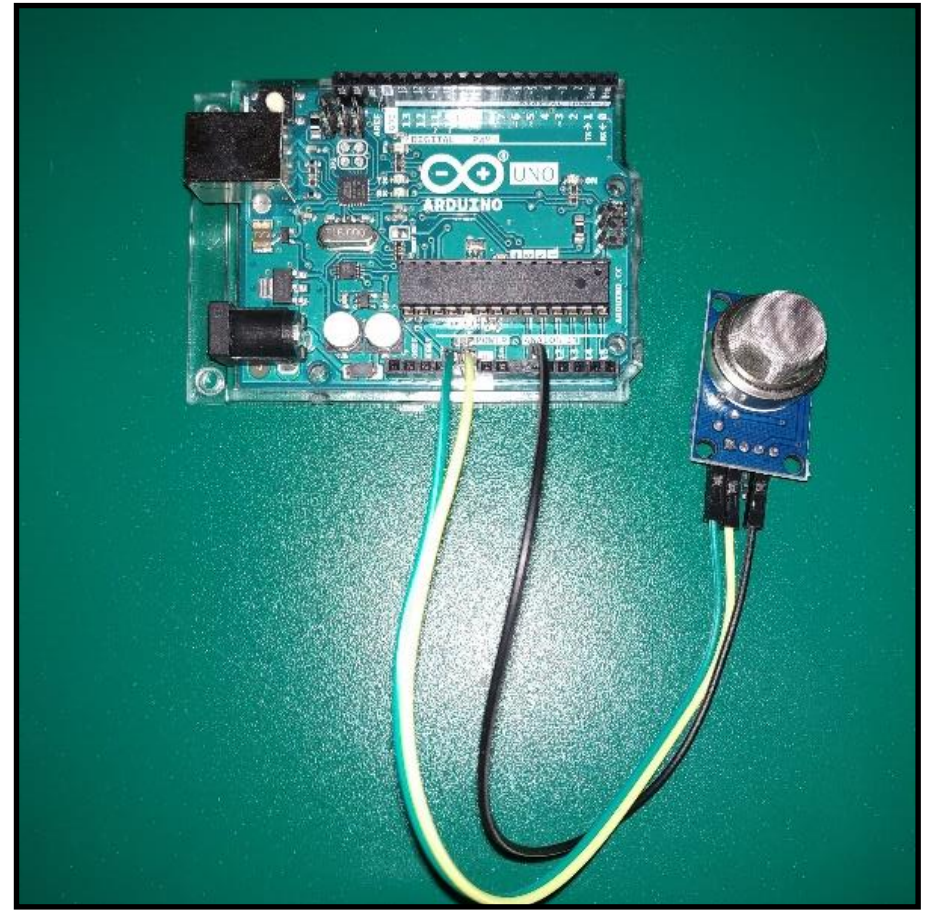

Gambar 5. Arduino Uno dan Sensor Gas Sesudah Dirangkai

2. Komunikasi Arduino Uno dan Sensor Api

Komunikasi Arduino dan sensor api digunakan untuk mendeteksi adanya nyala api atau tidak. Penulis menggunakan data analog agar Arduino dapat membaca nilai analog sensor ketika mendeteksi nyala api.

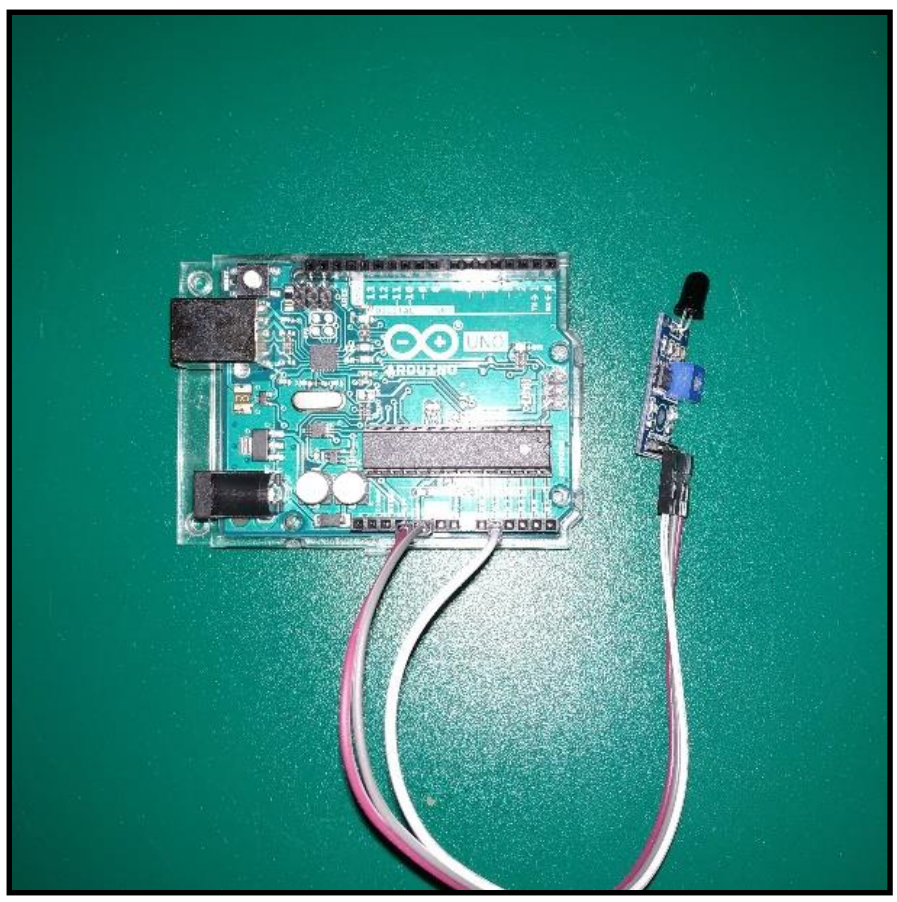

Gambar 6. Arduino Uno dan Sensor Api Sesudah Dirangkai 


\section{Komunikasi Arduino Uno dan Modul GSM SIM800L V2}

Komunikasi Arduino dan modul GSM digunakan untuk mengirimkan pemberitahuan bahwa telah terdeteksi adanya gas atau api lewat SMS. Penulis menggunakan pin digital sebagai jalur komunikasi antara arduino dan modul GSM.

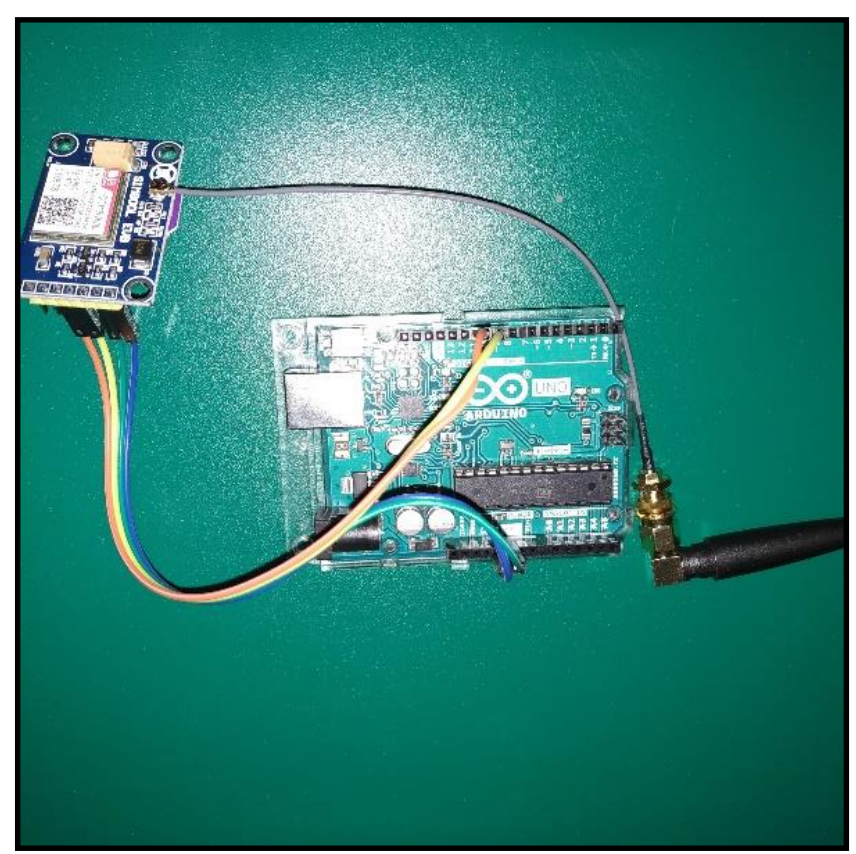

Gambar 7. Arduino Uno dan Modul SIM800L Sesudah Dirangkai

\section{Koneksi Arduino Uno dan Buzzer}

Koneksi Arduino dan buzzer digunakan sebagai alarm pemberitahuan bahwa telah terdeteksi adanya gas atau api. Penulis menggunakan pin digital karena untuk menyalakan buzzer tinggal diset ke mode "HIGH", dan untuk mematikan buzzer diset ke mode "LOW".

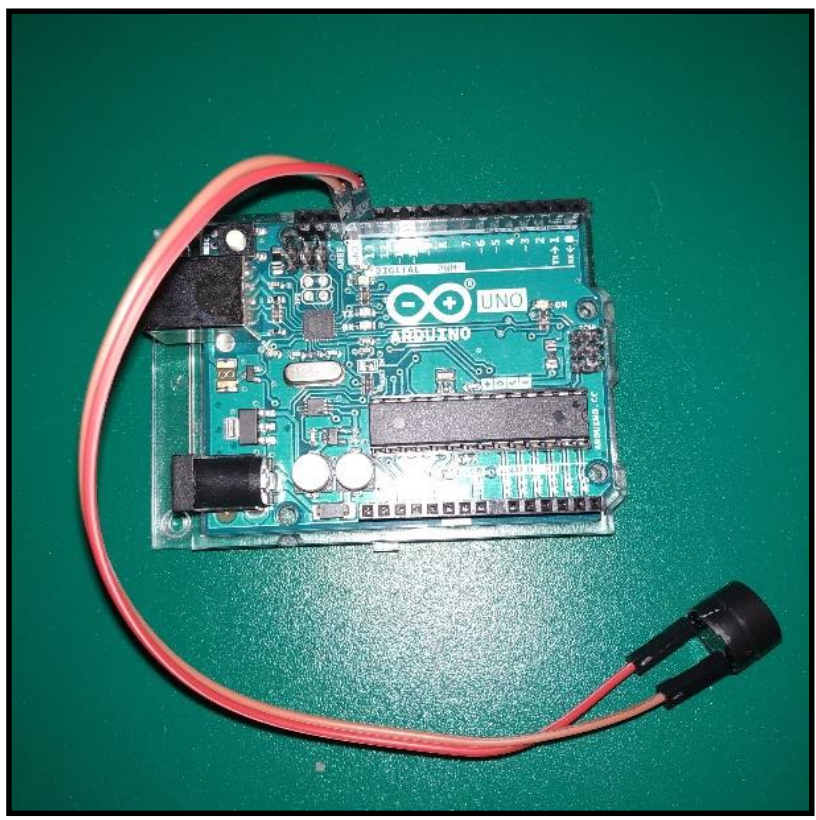

Gambar 8. Arduino Uno dan Buzzer Sesudah Dirangkai 


\subsubsection{Pengujian White Box Sensor Gas}

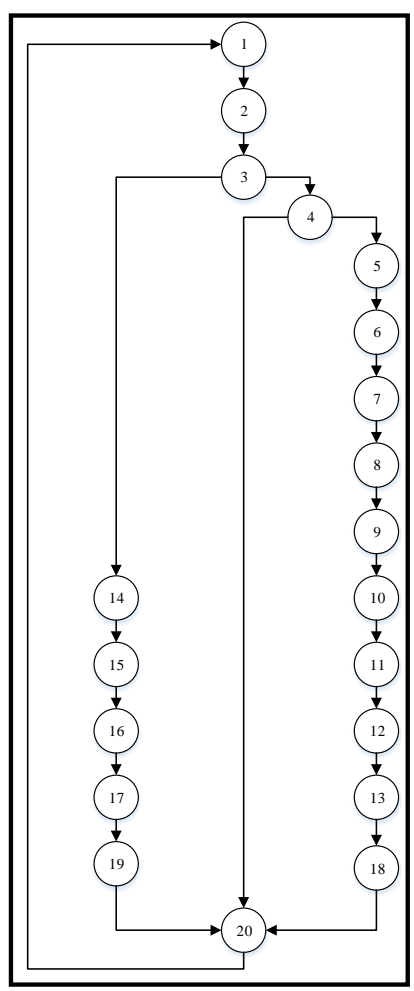

Gambar 9. Flow Graph Sensor Gas

Perhitungan white box :

1. Region $=4$

2. Cyclomatic Complexity :

a. $\quad \mathrm{V}(\mathrm{G})=$ Edge $($ Jumlah Busur $)-$ Node $($ Jumlah Simpul $)+2$

$\mathrm{V}(\mathrm{G})=22-20+2$

$\mathrm{V}(\mathrm{G})=4$

b. $\quad \mathrm{V}(\mathrm{G})=$ Predicate Node +1

$\mathrm{V}(\mathrm{G})=3+1$

$\mathrm{V}(\mathrm{G})=4$

3. Independent Path $=4$

Path $1: 1-2-3-4-15-16-17-18-20-21$

Path $2: 1-2-3-4-5-21$

Path 3 : 1-2-3-4-5-6-7-8-9-10-11-12-13-14-19-21

Path 4 : 1-2-3-4-15-16-17-18-20-21-2-3-4-5-21-2-3-4-5-6-7-8-9-10-11-12-13-14-19-21 


\subsubsection{Pengujian White Box Sensor Api}

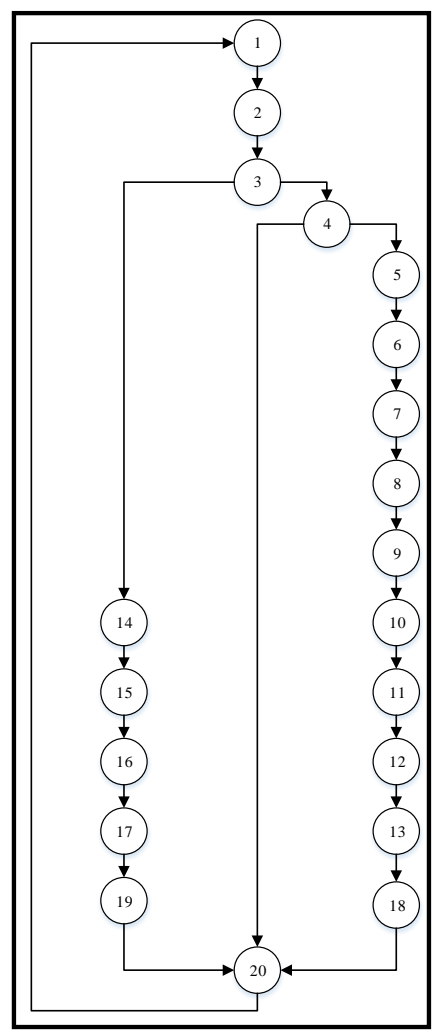

Perhitungan white box :

Gambar 10. Flow Graph Sensor Api

1. Region $=4$

2. Cyclomatic Complexity :

a. $\quad \mathrm{V}(\mathrm{G})=$ Edge (Jumlah Busur $)-$ Node (Jumlah Simpul) +2

$\mathrm{V}(\mathrm{G})=22-20+2$

$\mathrm{V}(\mathrm{G})=4$

b. $\quad \mathrm{V}(\mathrm{G})=$ Predicate Node +1

$\mathrm{V}(\mathrm{G})=3+1$

$\mathrm{V}(\mathrm{G})=4$

3. Independent Path $=4$

Path $1: 1-2-3-4-15-16-17-18-20-21$

Path $2: 1-2-3-4-5-21$

Path $3: 1-2-3-4-5-6-7-8-9-10-11-12-13-14-19-21$

Path 4 : 1-2-3-4-15-16-17-18-20-21-2-3-4-5-21-2-3-4-5-6-7-8-9-10-11-12-13-14-19-21

\section{KESIMPULAN DAN SARAN}

\subsection{Kesimpulan}

Berdasarkan penelitian yang dilakukan oleh peneliti melalui analisis yang dilakukan pada bab-bab sebelumnya, maka dapat diambil kesimpulannya adalah sebagai berikut :

1. Sistem ini dapat mendeteksi adanya kebocoran gas lpg di dapur rumah tangga dan berguna sebagai tindakan pencegahan terhadap kebakaran.

2. Sensor api dapat mendeteksi adanya kobaran api yang dapat menjadi penyebab kebakaran.

3. Sistem ini mengeluarkan alarm berupa bunyi dan memberikan pemberitahuan melalui sms jika terdeteksi kebocoran gas lpg atau kobaran api. 


\subsection{Saran}

Berdasarkan penelitian dan pembuatan alat yang penulis lakukan, maka penulis memberikan beberapa saran dan masukkan agar kedepannya alat ini bisa lebih baik lagi pada implementasinya, diantaranya:

1. Dapat mengirimkan pemberitahuan ke lebih dari satu nomor telepon.

2. Menambahkan layar lcd agar dapat menampilkan nilai gas dan api yang terdeteksi.

3. Dengan banyaknya modul yang terhubung dengan Arduino Uno, dianjurkan menggunakan adaptor power eksternal agar sistem bisa berjalan dengan baik.

\section{DAFTAR PUSTAKA}

[1] Dewabroto, Wiryanto. 2005. Aplikasi Rekayasa Konstruksi dengan Visual Basic 6.0. Jakarta: PT Elex Media Komputindo

[2] Dharmawan, Hari Arief. 2017. Mikrokontroler Konsep Dasar dan Praktis. Malang: UB Press

[3] Marimin. dkk. 2006. Sistem Informasi Manajemen Sumber Daya Manusia.Jakarta: Grasindo

[4] Mulya, Renaldy Rahardian. 2016. "Otomatisasi Penentuan Harga Berdasarkan Berat dan Volume Barang Pada Jasa Pengiriman”. Skripsi. Fakultas Vokasi. Program Studi D3 Otomasi Sistem Instrumentasi. Universitas Airlangga. Surabaya

[5] Risal, Ahmad. 2017. Mikrokontroler dan Interface. Fakultas Teknik. Pendidikan Teknik Elektronika. Universitas Negeri Makassar. Makassar.

[6] Sanjaya. 2016. "Perancangan Sistem Pendeteksi Kebakaran Menggunakan Arduino Mega ADK dan Sensor Berbasis SMS Gateway”. Skripsi. Fakultas Teknik. Program Studi Teknik Informatika. Universitas Bhayangkara Jakarta Raya. Jakarta.

[7] Utami, Ema., dan Sukrisno. 2005. 10 Langkah Belajar Logika dan Algoritma Menggunakan Bahasa $C$ dan $C++$ di GNU/Linux. Yogyakarta: ANDI

[8] Wicaksono, Mochamad Fajar, Hidayat. 2017. Mudah Belajar Mikrokontroler Arduino. Bandung: Informatika Bandung.

[9] Sinauarduino. (2016). Mengenal Arduino Software (IDE). Diakses pada 25 Mei 2018, dari https://sinauarduino.com/artikel/mengenal-arduino-software- ide/

[10] Rahmat, Ajang. (2014). Jenis-Jenis Microcontroller Arduino. Diakses pada 25 Mei 2018, dari https://kelasrobot.com/jenis-jenis-microcontroller-arduino/

[11] Webagus. (2018). Mengenal Komponen pada Papan Arduino Uno. Diakses pada 30 Juli 2018, dari https://www.webagus.id/2018/07/mengenal-komponen-pada-papan-arduino-uno_28.html

[12] Djuandi, Feri. (2011). Pengenalan Arduino. Diakses pada 16 April 2018, dari http://tobuku.com/index.php/2011/01/08/pengenalan arduino/

[13] AdminMikro. (2018). Sensor Asap Mq2 dengan Arduino, Karakteristik dan Prinsip Kerja Sebagai Deteksi Asap. Diakses pada 25 Mei 2018, dari https://mikroavr.com/sensor-asap-mq2-arduino/

[14] Kho, Dikcson. (2016). Pengertian Piezoelectric Buzzer dan Cara Kerjanya. Diakses pada 25 Mei 2018, dari https://teknikelektronika.com/pengertian-piezoelectric-buzzer-cara-kerja-buzzer/

[15] LabElektronika. (2018). Cara Program GSM Module SIM800L V2 Mengirim SMS Menggunakan Arduino. Diakses pada 25 Mei 2018, dari http://www.labelektronika.com/2018/01/cara-program-gsmmodule-sim8001-Kirim-SMS-Menggunakan-Arduino.html

[16] Pradana, Sunu. (2016). Mengenal Fritzing dan ExpressPCB. Diakses pada 26 Mei 2018, dari www.sunupradana.info/pe/2016/10/15/mengenal-fritzing-dan-expresspcb/

[17] https://www.arduino.cc/. (diakses 25 Mei 2018)

[18] http://fritzing.org/home/. (diakses 20 Mei 2018) 